\title{
Cebos envenenados contra perros y gatos en entornos urbanos $y$ públicos. Comentario sobre la aplicación del artículo 336 del Código Penal.
}

\author{
Marta Lezaola ${ }^{1}$
}

\section{SUMARIO}

1. INTRODUCCIÓN

2. EL ARTÍCULO 336 DEL CÓDIGO PENAL

2.1. Conceptos de "caza" y "fauna".

2.2. Presunción de la intención y el riesgo destructivo.

2.3. Bien jurídico protegido: la fauna y el ecosistema.

2.4. Delito de riesgo.

2.5. Muerte del animal como agravante o responsabilidad civil.

2.6. Delito indiciario.

3. LEGISLACIÓN Y JURISPRUDENCIA

4. CONCLUSIONES

APÉNDICE

\section{INTRODUCCIÓN.}

Se vienen repitiendo con demasiada asiduidad hechos consistentes en colocar cebos con algún tipo de veneno en parques, entornos urbanos y zonas públicas ${ }^{2}$. Estas prácticas deben ser tenidas en cuenta por su verdadera - y preocupante - naturaleza delictiva, al conllevar consecuencias negativas para el equilibrio ecológico, la biodiversidad y la salud pública. Se trata de acciones cometidas, en general, con una sensación de impunidad, y que requieren por tanto de una mayor persecución legal.

\footnotetext{
${ }^{1}$ Procurador de los Tribunales (Bizkaia). Licenciada en Derecho. Curso de Medio Ambiente en Escuela de Práctica Jurídica del Ilustre Colegio de Abogados de Vizcaya. Auxiliar de Clínica Veterinaria y Ayudante Técnico Veterinario. Activista y voluntaria en iniciativas de protección y defensa animal: gestión de colonias felinas; decomiso de animales en casos de maltrato; solicitudes a la Administración para la inspección de centros, identificación de animales o control de envío de animales al extranjero, entre otras. http://www.procuradordeanimales.com/

${ }^{2}$ Véase in fine apéndice de noticias.
} 
Es cierto que en virtud del Código Civil español ${ }^{3}$, en sus artículos 333 y ss., los animales son considerados cosas, y que con frecuencia las actuales leyes de protección animal encuentran importantes límites en intereses distintos e incluso contrarios a los de los animales. Sin embargo, aun siendo precisas muchas mejoras, la legislación actual nos proporciona herramientas para poder luchar contra el maltrato animal en nuestra sociedad. Y actuaciones como las descritas al inicio, cada vez más cotidianas, pueden ser abordadas con firmeza ante los tribunales a través del artículo 336 del Código Penal.

Las personas que realizan estos actos, o las que sólo son conocedoras o testigos de los mismos, lo hacen seguramente en la creencia de no poder ser perseguidos por ningún ilícito, o de cometer algo de poca gravedad. Sin embargo, como veremos, estamos ante un delito regulado en el Código Penal: Los ciudadanos deben saber que si han envenenado a un perro o gato, independientemente de quién sea su propietario, éste hecho está castigado por el Código Penal, con una pena de dos años de prisión, a la que en su caso se sumará la responsabilidad civil consistente en el pago de los animales envenenados y/o gastos de curación, así como las correspondientes costas.

Así, aunque el art. $336 \mathrm{CP}$ se ha venido aplicando casi exclusivamente en zonas naturales, fincas, cotos de caza..., la colocación de cebos envenenados en entornos urbanos resulta si cabe aún más grave, si consideramos el riesgo añadido que supone no sólo para los animales con los que convivimos, sino también para el resto de vecinos humanos. Por todo ello, resulta de vital importancia que los ciudadanos o asociaciones que sean conocedores de la colocación de algún tipo de veneno lo pongan en conocimiento de las autoridades, así como que éstas impulsen la investigación y persigan el delito. Sin denuncia, estos graves casos siguen aumentando, para quedar en meras noticias de prensa o, lo que es peor, sin llegar a conocerse, en una falsa apariencia de buen derecho.

\section{EL ARTíCULO 336 DEL CÓdigo PENAL.}

\footnotetext{
${ }^{3}$ http://www.derechoanimal.info/bbdd/Documentos/605.doc
} 
Artículo 336. El que, sin estar legalmente autorizado, emplee para la caza o pesca veneno, medios explosivos $u$ otros instrumentos o artes de similar eficacia destructiva o no selectiva para la fauna, será castigado con la pena de prisión de cuatro meses a dos años o multa de ocho a veinticuatro meses $y$, en cualquier caso, la de inhabilitación especial para profesión u oficio e inhabilitación especial para el ejercicio del derecho a cazar o pescar por tiempo de uno a tres años.

Como introducción, toda vez que se pretende demostrar la aplicación de este artículo a los envenenamientos que vienen sufriendo los animales domésticos y domesticados o silvestres en zonas urbanas, es importante recordar el capítulo en el que dicho precepto se encuentra: Capítulo IV. De los delitos relativos a la protección de la flora, fauna y animales domésticos.

El art. $336 \mathrm{CP}$ es el antecesor directo del artículo que pena de forma más grave el maltrato a animales domésticos, el art. $337 \mathrm{CP}$, con el cual, en el caso de animales domésticos, existiría concurso. La acción típica del art. $337 \mathrm{CP}$ consiste en el maltrato injustificado a animales domésticos o amansados, que puede producirse por cualquier medio o procedimiento, de manera que también cabría su comisión por envenenamiento.

No obstante, en los casos de utilización de venenos resulta especialmente acertada la aplicación del art. $336 \mathrm{CP}$, además de por el método utilizado y la no necesidad de muerte o lesiones del animal, por la mayor pena impuesta dada su repercusión al medio ambiente y que puede llegar hasta los 2 años de prisión (frente al máximo de un año de prisión previsto en el art. 337 CP). Igualmente debe mencionarse la prohibición para caza, oficio o profesión del condenado que prevé este artículo, y que resulta de gran relevancia, en cuanto que, según el perfil del autor, contribuye a garantizar que no se repitan los hechos.

Por último, si hay muerte de animal/es propiedad de tercero también podría aplicarse el art. 263 CP, por un delito de daños, considerando los hechos desde el punto de vista de la pérdida patrimonial producida, y por supuesto siendo diferente el bien jurídico protegido.

A continuación vamos a realizar un análisis detenido del contenido del art. 336 CP, atendiendo a los siguientes puntos:

- 2.1. Conceptos de "caza" y "fauna".

- 2.2. Presunción de la intención y el riesgo destructivo.

- 2.3. Bien jurídico protegido: la fauna y el ecosistema.

- 2.4. Delito de riesgo.

- 2.5. Muerte del animal como agravante o responsabilidad civil.

- 2.6. Delito indiciario. 


\subsection{Conceptos de "caza" y "fauna".}

Si bien la utilización de los estrictos términos empleados por el legislador "cazar" y "pescar" pueden llevar a confundir inicialmente sobre la aplicación de este artículo a los hechos que estamos analizando (veneno dirigido a animales domésticos en zonas urbanas), es necesario analizar bien qué significan ambos conceptos, al tiempo que tener en cuenta que en la redacción del tipo también se utiliza la expresión "para la fauna".

Los arts. 148 y 149 de la Constitución Española reservan al Estado la competencia para dictar legislación en materia de protección al medio ambiente, sin perjuicio de que las Comunidades Autónomas puedan establecer normas adicionales. En base a dicha previsión, la mayoría de las CCAA han asumido competencias en esta materia, y concretamente sobre caza, a través de regulaciones específicas. Así, el RD 1095/1989, de 8 de septiembre, regula en España las especies objeto de caza y pesca, relación de la que las CCAA pueden excluir o incluir especies ${ }^{4}$.

Sin embargo, aunque la vigente legislación sobre caza recoge el listado de los animales susceptibles de tal práctica, en realidad el término "fauna" engloba a todos los animales. La Real Academia Española define "fauna" como "el conjunto de animales de un país o región", y "animal" como "ser orgánico que vive, siente y se mueve por propio impulso". De lo cual debe concluirse que el mismo estarían incluidos tanto los animales domésticos, como los domesticados y los de compañía.

En lo que se refiere al concepto de caza, tomando como ejemplo la Ley 2/2011, de 17 de marzo, de caza en la Comunidad Autónoma del País Vasco ${ }^{5}$, en la misma se establece:

"Es acción de cazar la ejercida por las personas mediante uso de artes, armas, animales, 0 medios homologados apropiados para buscar, atraer, perseguir o acosar a los animales, con el fin de darles muerte, apropiarse de ellos o de facilitar su captura por tercera, así como la ejecución de los actos preparatorios que resulten directamente necesarios para esos fines" (art. 2 Ley 2/2011, de Caza, del País Vasco).

Y en relación con la ocupación de los animales cazados, "la pieza se entiende ocupada en el momento de su muerte" (art. 4.2 del mismo texto legal).

En cuanto a las zonas en que están cometiéndose estos delitos, las propias leyes autonómicas de caza hacen mención a la caza en núcleos urbanos. Siguiendo con el ejemplo de la referida Ley vasca de Caza, ésta regula de forma clara las zonas de seguridad en que estaría prohibido cazar, por el riesgo añadido que esto supone. Como tales zonas de seguridad contempla: las vías y caminos de uso público, los núcleos urbanos y rurales, las casas rurales, los edificios habitables aislados, zonas de acampada, recintos deportivos al

\footnotetext{
${ }^{4}$ http://www.derechoanimal.info/bbdd/Documentos/164.doc

${ }^{5}$ http://www.derechoanimal.info/bbdd/Documentos/903.pdf
} 
aire libre, parques..., entre otras (art. 27). Al mismo tiempo, esta Ley prohíbe expresamente: "El uso de veneno, cebos envenenados o no, gases o sustancias asfixiantes, incluido el humo, paralizantes, tranquilizantes, atrayentes o repelentes, así como los explosivos" (art. 38).

Teniendo en cuenta lo anterior, el hecho de que se estén colocando cebos envenenados en espacios públicos, concretamente en parques frecuentados por niños o en entornos y centros urbanos, lejos de no ser punible penalmente constituye un riesgo añadido y una agravante por los que estas conductas deben ser perseguidas.

\subsection{Presunción de la intención y el riesgo destructivo.}

Nos encontramos ante un delito de riesgo, ya que con la sola utilización del veneno, se presume su eficacia destructiva o el riesgo de destrucción que su mero uso lleva aparejado.

La persona que utiliza el veneno, y la sociedad en general, conocen que el veneno es mortal. De este modo, en este tipo de delito no es necesario probar el dolo o intención, porque quien coloca o esparce veneno o cebos envenenados lo hace a sabiendas de sus consecuencias y, por tanto, con la clara intención de envenenar.

Además, en los casos de colocación de estas sustancias en entornos urbanos, el cebo o alimento suele ser elegido premeditadamente por el autor, dependiendo de a qué animal pretenda dar caza o muerte, siendo la elección normalmente la colocación de sardinas para envenenar a los gatos, y la colocación de morcillas, salchichas u otro embutido para envenenar a los perros.

\subsection{Bien jurídico protegido: la fauna y el ecosistema.}

El bien jurídico protegido en el 336 CP no son sólo los animales de forma individual, sino como conjunto de seres vivos que forman la biodiversidad. Así, se protege el daño o peligro que se puede provocar al equilibrio del ecosistema por los medios empleados. Se protege el medio ambiente y la vida en sentido amplio, en el que quedan incluidos también los animales domésticos.

El veneno se introduce en la cadena trófica de una forma incontrolada con un potencial lesivo que va más allá de la afectación a la fauna, y no deja posible salvación 
a animales exterminando a todos, con lo que incide de forma muy importante en todo el ecosistema, lo que supone un ataque de especial importancia al bien jurídico protegido.

El veneno al no ser selectivo, es susceptible de provocar daños en todas las especies, la muerte de animales domésticos y de especies protegidas, envenenamientos en humanos y contaminación del suelo ${ }^{6}$.

\subsection{Delito de riesgo.}

Se trata de un delito de riesgo o de mera actividad, para cuya aplicación basta con el empleo de los medios. Así, no se exige la muerte del animal para que el autor pueda ser condenado.

Como se ha dicho anteriormente, lo que caracteriza al veneno es su potencialidad lesiva, tanto por su carácter no selectivo e indiscriminado, como por la imposibilidad de control de sus efectos devastadores y destructivos, capaces de acabar con especies de todo tipo.

\subsection{Responsabilidad civil o agravante.}

El que se produzca la muerte de un animal se valora a los efectos de reparación del daño o responsabilidad en favor del propietario, o para aplicar la agravante:

Art. 336.2 CP. Si el daño causado fuera de notoria importancia, se impondrá la pena de prisión antes mencionada en su mitad superior.

Para ello se tienen en cuenta criterios cuantitativos, como el número de animales afectados o muertos, así como criterios de riesgo para la biodiversidad, al afectar a otro tipo de animales, plantas, zonas protegidas y animales protegidos o en riesgo de extinción. En los casos concretos que estamos analizando, que tienen lugar en núcleos urbanos, hay además un especial riesgo para el ser humano que también debe ser considerado.

\footnotetext{
${ }^{6}$ Véase Proyecto Life + VENENO. SEO/Birdlife. http://www.venenono.org/
} 
En el caso de animales abandonados o urbanos (por ejemplo, gatos de colonias controladas), la aplicación de la agravante y la reparación del daño por el número de animales muertos y el riesgo creado en el municipio debería ser, como entidad responsable de los mismos, el propio Ayuntamiento.

\subsection{Delito indiciario}

Una de las mayores problemáticas con que nos encontramos en este tipo de delito, reside en la prueba de su autoría, ya que los mismos se cometen en ausencia de testigos. Esta dificultad de poder probar quién ha depositado el veneno, suele ser la principal causa de archivo de las denuncias por este tipo de hechos ${ }^{7}$.

Nos encontramos, por tanto, ante un delito indiciario, que debe ser basado en pruebas de igual carácter, tales como:

- Animales muertos en la zona comunitaria/pública, parque...

- Presencia de cebos envenenados o veneno (prueba crucial).

- Declaraciones de los agentes de policía.

Estas declaraciones son complementarias. Los agentes de policía deben ser llamados para personarse en el lugar y levantar el correspondiente atestado o informe escrito, en el que se constará la presencia del veneno y se recogerán los datos del denunciante y testigo/s, así como fotografías.

- Autopsia de los animales muertos.

Se deben llevar cuerpos del animal/es a la Clínica Veterinaria que realizara un Informe determinante del nexo causal entre el veneno y el tipo de este y la muerte del animal.

- Análisis de los cebos o del veneno.

- Titularidad de la finca o del suelo en que se encuentra el animal, o donde el veneno haya aparecido.

7 Por este motivo el Juzgado $\mathrm{n}^{\circ} 1$ de Palencia archivó las diligencias abiertas a raíz de los casos de envenenamiento de perros por carbofurano en distintos parques de Palencia, en primavera y verano de 2010. http://www.abc.es/agencias/noticia.asp?noticia=1248702 
El titular de dicha finca o suelo podrá ser imputado con la prueba indiciaria de que hayan aparecido en su propiedad. Esta posibilidad de prueba indiciaria es especialmente relevante para el caso concreto de los Ayuntamientos, si entendemos que los animales abandonados o urbanos son responsabilidad de las administraciones públicas locales, en virtud de las competencias que sobre los mismos les otorgan las legislaciones autonómicas en la materia. Esta consideración debe añadir si cabe más fuerza al deber de las corporaciones locales de perseguir este tipo de conductas, en el sentido de investigar, informar y prevenir sobre estos delitos en sus municipios, otorgándoles la importancia y gravedad que merecen.

\section{LEGISLACIÓN Y JURISPRUDENCIA.}

Entre la legislación que regula el tipo de veneno y animales aplicables a estos casos podemos encontrar la Ley 42/2007, de 13 de diciembre, del Patrimonio Natural y de la Biodiversidad en su Anexo $\mathrm{VII}^{8}$, la Directiva 92/43/CEE, del Consejo, de 21 de mayo de 1992, relativa a la Conservación de los Hábitats Naturales y de la Fauna y Flora Silvestres ${ }^{9}$, y el Convenio de Berna relativo a la Conservación de la Vida Silvestre y el Medio Natural en Europa ${ }^{10}$.

Dado lo novedoso de la aplicación del art. 336 CP respecto de los animales domésticos y domesticados en zonas urbanas, hasta la fecha existe escasa jurisprudencia al respecto, encontrándose casos en fase de instrucción e investigación, o en sentencia del Juzgado de lo Penal. A continuación se citan algunos ejemplos:

- En junio de 2014, tras la denuncia de un vecino, el SEPRONA de la Guardia Civil investigó los hechos y el Juzgado de Instrucción no 3 de Burgos imputó a una anciana de 71 años por matar a seis gatos ${ }^{11}$.

- En julio de 2013 el Juzgado de lo Penal no 1 de Logroño dictó sentencia condenatoria por introducir veneno en unos conejos muertos, y matar entre otros animales a dos

\footnotetext{
${ }^{8}$ http://www.derechoanimal.info/bbdd/Documentos/180.pdf

${ }^{9}$ http://www.derechoanimal.info/bbdd/Documentos/841.pdf

${ }^{10}$ http://www.derechoanimal.info/bbdd/Documentos/53.pdf

11 http://www.derechoanimal.info/esp/page/3292/imputada-por-presunto-delito-de-maltrato-animal-porel-envenenamiento-de-seis-gatos
} 
perros de los vecinos, así como a dos gatos, y se le impuso la pena de un año de prisión y dos de inhabilitación especial para el ejercicio del derecho a cazar ${ }^{12}$.

- En septiembre de 2013 el Juzgado de lo Penal no 2 de Ciudad Real dictó una sentencia condenatoria contra un hombre por envenenar a los perros de su inquilino, siendo condenado a cuatro meses de prisión e inhabilitación del ejercicio de la caza durante un año por la comisión de un delito contra la fauna, así como al pago de una multa de $900 €$ por un delito de daños ${ }^{13}$.

- En octubre de 2013 el Juzgado de Instrucción no 6 de Ciudad Real imputó a un vecino por matar dos gatos, mezclando atún con veneno.

- En diciembre de 2011 el Juzgado de lo Penal no 3 de Murcia condenó por un delito contra la fauna previsto y penado en el art. $336 \mathrm{CP}$, por colocar carne con veneno y matar entre otros animales a dos perros.

Por su parte, la mayoría de las sentencias de la Audiencia Provincial se refieren a cotos de caza y animales protegidos, pero desde hace varios años ya hacen referencia y mencionan a los animales domésticos que se encuentran entre los envenenados, lo que es un paso alentador y acreditativo para expandir la aplicación a estos últimos. Así, por ejemplo:

- Sentencia de la Audiencia Provincial de Ciudad Real, núm. 10/2011, en la que el condenado mató con animales a muchos animales protegidos, mencionando entre ellos a un perro ${ }^{14}$.

- Sentencia no 284/2012 de AP Murcia, Sección 2åa de 29 de junio de 2012, en la que el condenado se dedicaba a la gestión y aprovechamiento de un coto, y mató esparciendo morcillas con veneno a muchos animales mencionando entre ellos a dos perros $^{15}$.

\section{CONCLUSIONES}

En los doce últimos años como miembro de una Asociación de Protección Animal, vemos cómo los casos de envenenamientos en zonas urbanas están aumentando, dirigidos por cierto de

\footnotetext{
${ }^{12}$ http://www.elcorreo.com/alava/v/20130721/rioja/condenado-prision-envenenar-perros-20130721.html

${ }^{13}$ http://www.derechoanimal.info/bbdd/Documentos/1226.pdf

${ }^{14} \mathrm{http} / / / \mathrm{www} . d e r e c h o a n i m a l . i n f o / b b d d / D o c u m e n t o s / 1510 . p d f$

${ }^{15}$ http://www.derechoanimal.info/bbdd/Documentos/966.pdf
} 
forma muy destacable a la aniquilación masiva o caza de colonias de gatos, seres con quienes convivimos y compartimos las zonas urbanas. Con frecuencia se pone de manifiesto que la motivación por la que pretenden justificarse estos actos reside en las molestias que algunos ciudadanos encuentran en los animales que conviven en el mismo municipio, bien perros o, como decimos, gatos pertenecientes a colonias urbanas ${ }^{16}$. De acuerdo con lo expuesto anteriormente, este tipo de actos tienen encaje y deberían ser denunciados en aplicación del art. $336 \mathrm{CP}$.

Los delitos comprendidos en el Capítulo IV del Título XVI del Código Penal dan cumplimiento a lo dispuesto en el art. 45 de la Constitución Española, protegiendo el medio ambiente a través de la tutela de la flora y la fauna. Detrás de la conducta delictiva tipificada en el art. 336 CP puede observarse un desprecio a la vida en el sentido más amplio, por la repercusión global de estos actos al hábitat, incluyendo también a animales domésticos y domesticados, y especialmente en las zonas públicas y núcleos urbanos, como zonas de riesgo prohibidas en la propia legislación de caza.

La persecución y prevención de este tipo de delitos debe hacerse de oficio por las Administraciones, como poseedoras de los instrumentos y medios adecuados para hacerlo, sobre todo buscando un efecto disuasorio, a fin de evitar que la situación se agrave y que los autores crezcan en sensación de impunidad. No obstante, son también importantes las denuncias particulares para poner en marcha el proceso judicial.

En octubre de 2013 en Gernika (Bizkaia), fue esparcido veneno para ratas mezclado con carne en los parques del municipio. En el mes de noviembre de $2014^{17}$ se volvía a repetir la

${ }^{16}$ Resulta muy ilustrativo, en ese sentido, un mensaje encontrado en las redes sociales a raíz de la publicación de una noticia sobre la colocación de veneno en los parques de un pueblo de Cáceres, por lo que murieron varios perros: “Cuando la policía y la justicia no actúa, lo hace el pueblo a su manera. Esperemos que por lo menos sirva para concienciar que tenemos derecho a pasear sin oler meadas de perros ni pisar sus cagadas".

${ }^{17}$ http://www.elcorreo.com/vizcaya/20131008/local/esparcen-veneno-para-ratas-201310081331.html 
actuación, esta vez utilizando sardinas con matarratas, con lo que apareció una colonia de gatos muertos. En este caso, es importante mencionar que el municipio se encuentra enclavado en la zona de Urdaibai, Reserva de la Biosfera, bajo el amparo de la Ley 16/1994, de 30 de junio, de Conservación de la Naturaleza del País Vasco, que protege los parques naturales terrestres como uno de los ecosistemas más emblemáticos y de mayor valor natural de la Comunidad, que albergan especies protegidas y son zona de paso de aves y anidada de especies migratorias protegidas. Los hechos fueron denunciados por una asociación de protección animal.

En este caso llamó especialmente la atención el mensaje que desde el Ayuntamiento fue difundido a través de los medios de comunicación, que se limitó a publicar que se había esparcido veneno para ratas mezclado con carne en los parques del municipio, alertando de la obligación de los propietarios de perros de llevarlos con correa, y anunciando que por la Policía municipal se harían campañas de vigilancia de la retirada de las cacas y tenencia de microchip. Ante esto, es importante insistir en la importancia de la actuación administrativa frente a estos hechos $y$, en consecuencia, en la gravedad de su inactividad, por la sensación de justificación del acto y, aún peor, de impunidad del mismo, que se traslada a la sociedad.

Por último, debemos destacar el art. 339 CP, el cual refleja la verdadera importancia y consecuencias de estos delitos, de forma que la ley, en lugar de limitarse a la sanción, pone verdadero énfasis en la necesidad de protección y restauración del equilibrio biológico a cargo del autor del hecho:

Artículo 339 CP. Los jueces o tribunales ordenarán la adopción, a cargo del autor del hecho, de las medidas necesarias encaminadas a restaurar el equilibrio ecológico perturbado, así como de cualquier otra medida cautelar necesaria para la protección de los bienes tutelados en este Título.

La colocación de cebos envenenados en parques públicos es, en definitiva, una práctica cruel, cobarde e indiscriminada que representa un peligro para el medio ambiente, los animales domésticos, los urbanos silvestres libres, y los humanos. Una práctica que está prohibida por la legislación y la normativa autonómica y europea, y que, a través del art. 336 CP analizado, está tipificada como delito en el Código Penal. Es un delito público.

Bilbao, enero 2015.

\section{APÉNDICE.}


Relación de ejemplos de noticias de prensa aparecidas en los últimos años, sobre casos de envenenamientos en parques públicos.

- Preocupación por el envenenamiento de perros en parques públicos de Gijón (La Nueva España. 16-11-2014).

http://www.Ine.es/gijon/2014/11/16/preocupacion-envenenamiento-perrosparques/1672144.html

- Investigan varios casos de envenenamiento de mascotas (Zigzagdigital. 23-06-2014) http://zigzagdigital.com/not/7898/investigan varios casos de envenenamiento de mas cotas/

- Huellas denuncia el envenenamiento de perros y gatos en la zona de la calle Ancha en Puertollano (La Comarca, 25-08-2013).

http://www.lacomarcadepuertollano.com/diario/noticia/2013 08 25/24

- Cinco perros mueren por envenenamiento en Lekeitio (Diario Vasco. 27-07-2013) http://www.diariovasco.com/20130727/mas-actualidad/sociedad/perros-envenenados201307271534.html

- Nuevos casos de envenenamiento de perros en los parques públicos. (La Rioja.com. 0310-2010). http://www.larioja.com/v/20101003/rioja-logrono/nuevos-casos-envenenamientoperros-20101003.html

- Envenenamiento De Perros En La Urbanización Los Balcones De Torrevieja (TorreviejalP. 13-09-2007)

http://www.torreviejaip.tv/sucesos/20070913132/envenenamiento-de-perros-en-laurbanizacion-los-balcones-de-torrevieja.html

- La muerte por envenenamiento de nueve perros provoca el cierre de los parques en Abadiño (20 minutos. 20/10-2006).

http://www.20minutos.es/noticia/164671/0/envenenados/perros/abadino/ 